\title{
Mean Platelet Volume and Uric Acid Levels in Neonatal Sepsis: Correspondence II
}

\author{
Ercan Varol
}

Received: 21 April 2014 / Accepted: 9 June 2014 / Published online: 1 July 2014

(C) Dr. K C Chaudhuri Foundation 2014

To the Editor: I read the article published by Aydin et al. with a great interest [1]. They assessed the mean platelet volume (MPV) in clinical neonatal sepsis (NS) (Group I), cultureproven NS (Group II) and healthy controls (Group III). MPV values were higher in Group I and Group II when compared to Group III, although there was no difference between Groups I and II.

The patients in Group II had the highest C-reactive protein (CRP) levels, lowest platelet counts and lowest uric acid levels when compared to Groups I and III. I congratulate the authors for this well designed and written study. On the other hand, I want to make minor criticism about this study from methodological aspect.

Firstly, MPV measurement technique is not clear. They did not mention about the tube in which blood sample was collected and did not mention about the time interval between blood sampling and analysis. This time interval is important in use of ethylene diamine tetra acetic acid (EDTA) anticoagulated tubes. MPV increases over time in EDTAanticoagulated samples and this increase is shown to be proportional with the delay in time between sample collection and laboratory analysis. With impedance counting, the MPV increases over time as platelets swell in EDTA, with increases of $7.9 \%$ within 30 min having been reported and an overall increase of $13.4 \%$ over $24 \mathrm{~h}$, although the majority of this increase occurs within the first $6 \mathrm{~h}$ [2]. The recommended optimal measuring time of MPV is maximum $120 \mathrm{~min}$ after venipuncture. For reliable MPV measurement, the potential influence of anticoagulant on the MPV must be carefully controlled by standardizing the time delay between sampling and analysis (less than $2 \mathrm{~h}$ ).

E. Varol $(\bowtie)$

Department of Cardiology, Faculty of Medicine, Suleyman Demirel

University, Isparta, Turkey

e-mail: drercanvarol@yahoo.com
Secondly, there is association of MPV with hypothyroidism [3]. The authors did not mention about any possible presence of neonatal hypothyroidism. It has been shown that hypothyroidism increases MPV values [3]. Absolutely, this factor should be considered in MPV assessment in newborns like adults. MPV might be a link between thrombosis and inflammation. Inflammatory reaction in neonatal sepsis can be the major cause of increased MPV values [4]. However, all confounding factors should be taken into account and standardized methods must be used in MPV measurement [5].

\section{Conflict of Interest None.}

Source of Funding None.

\section{References}

1. Aydın B, Dilli D, Zenciroğlu A, Karadağ N, Beken S, Okumuş N. Mean platelet volume and uric acid levels in neonatal sepsis. Indian J Pediatr. 2014. doi:10.1007/s12098-014-1417-4.

2. Lancé MD, van Oerle R, Henskens YM, Marcus MA. Do we need time adjusted mean platelet volume measurements? Lab Hematol. 2010;16:28-31.

3. Erikci AA, Karagoz B, Ozturk A, Caglayan S, Ozisik G, Kaygusuz I, et al. The effect of subclinical hypothyroidism on platelet parameters. Hematology. 2009;14:115-7.

4. Gasparyan AY, Ayvazyan L, Mikhailidis DP, Kitas GD. Mean platelet volume: a link between thrombosis and inflammation? Curr Pharm Des. 2011;17:47-58.

5. Park Y, Schoene N, Harris W. Mean platelet volume as an indicator of platelet activation: methodological issues. Platelets. 2002;13:301-6. 